\title{
Review
}

\section{Epidemiology of chronic non-cancer pain in Europe: narrative review of prevalence, pain treatments and pain impact}

Kim J. Reid

KJ Research, Rosemère, Québec, Canada

Julie Harker

Kleijnen Systematic Reviews Ltd, York, UK

Malgorzata M. Bala

Department of Internal Medicine, Jagiellonian University Medical College, Krakow, Poland

Carla Truyers

Academic Department of General Practice, Katholieke Universiteit Leuven, Belgium

Eliane Kellen

Leuven Centre for Cancer Prevention, University Hospital Leuven, Belgium

Geertruida Elsiena Bekkering

BeSyRe Bekkering Systematic Reviews, Geel, Belgium; Center for Evidence Based Medicine, Katholieke Universiteit Leuven, Leuven, Belgium

\section{Jos Kleijnen}

School for Public Health and Primary Care (CAPHRI), University of Maastricht, Maastricht, The Netherlands Kleijnen Systematic Reviews Ltd, York, UK

\section{Address for correspondence:}

Jos Kleijnen, MD, PhD, Kleijnen Systematic Reviews Ltd, Unit 6 Escrick Business Park, Riccall Road, Escrick, York Y019 6FD, UK.

Tel.: +44 (0)1904 727980; Fax: +44 (0)1904

720429; jos@systematic-reviews.com

\section{Key words:}

Epidemiology - Pain - Patient compliance -

Prevalence - Quality of life - Therapy

Accepted: 3 December 2010; published online: 3 January 2011 Citation: Curr Med Res Opin 2011; 27:449-62

\section{Abstract}

Background:

Estimates on the epidemiology of chronic non-cancer pain vary widely throughout Europe. It is unclear whether this variation reflects true population differences or methodological factors. Such epidemiological information supports European decision makers in allocating healthcare resources.

\section{Objective:}

Pan-Europe epidemiological data about chronic non-cancer pain was obtained using systematic review principles in searching and summarising results.

\section{Methods:}

Multiple databases (MEDLINE, EMBASE, Cochrane Library, CRD Databases, and GIN) were systematically searched for primary studies containing epidemiological data on chronic non-cancer pain in Europe excluding studies that solely concerned migraines, headaches and pain associated with specific disease conditions. The studies were prioritised according to quality, recency and validity.

\section{Main outcomes:}

Eighteen research questions concerning aspects of chronic pain included: prevalence; incidence; pain treatments, control and compliance; treatment satisfaction; and quality of life and economic impacts.

Results:

The search yielded 16619 references and 45 were relevant to Europe. Studies for each question were selected that provided the most recent, representative and valid data. There was a clear lack of studies concerning chronic non-cancer pain in Europe as a whole. The 1-month prevalence of moderate-to-severe non-cancer chronic pain was 19\%. Chronic pain significantly impacted on patient-perceived health status, affected everyday activities including economic pursuits and personal relationships, and was significantly associated with depressive symptoms. The majority relied on drugs for pain control and NSAIDs were the most frequent drug choice. Despite pain medications, a large proportion had inadequate pain control.

\section{Conclusion:}

To the authors' knowledge this is the most comprehensive literature review on epidemiological data in this field. It is clear that chronic pain has a dramatic impact on European society. Since chronic non-cancer pain is treated differently from cancer-related pain, the lack of data in this area clearly underlines the need for decision makers in healthcare to gather further epidemiological data.

\section{Introduction}

Chronic pain represents a public health problem in Europe with an evident social and economic impact, although a paucity of reliable data about its 
epidemiology hinders an accurate estimation of the burden of this condition. Prevalence estimates vary widely and typically range between 10 and $30 \%$ of an adult population, although studies have reported it as low as $2 \%$ and as high as $50 \%{ }^{1-3}$. This wide variation may reflect true differences between populations, but may also depend on how chronic pain is defined and the assessment methods used in epidemiological studies.

With respect to chronic non-cancer pain in Europe, reliable and valid epidemiological data are scarce; although, the pain relief treatments for cancer-related chronic pain are notably different than non-cancer pain ${ }^{4}$. The World Health Organization three-step ladder for pain relief has been used to successfully treat cancerrelated pain but opioids still are considered controversial for those with chronic non-cancer pain because of concerns about efficacy, safety, addiction or abuse, and regulatory body disapproval ${ }^{4-6}$. Chronic non-cancer pain can include both nociceptive and neuropathic pain that may be affected by psychological and/or socio-environmental factors. Typical locations of chronic non-cancer pain include upper and lower back, head and neck, and joints. It is often reported to be more common in older age groups, lower income groups and among women ${ }^{7-10}$.

Information about the epidemiology of chronic noncancer pain is important to help European decision and policy makers decide about health budgets and prioritisation, patient segmenting and budget fencing. As chronic non-cancer pain is an important medical and public health issue, there is a need for better understanding of the burden of disease and current treatment practice within Europe as a whole.

This study aimed to obtain epidemiological data about chronic non-cancer pain within Europe, while excluding studies exclusively about pain associated with migraines, headaches and specific disease conditions such as multiple sclerosis. The authors aimed to review the most relevant scientific literature, using the principles of systematic reviews in searching and critically summarising the findings. Studies were prioritised and selected according to relevance, recency and validity, rather than summarising the results of all studies that were identified.

\section{Methods}

This pan-Europe review was developed within the framework of a broader review about the epidemiology of chronic non-cancer pain within individual European countries. The aim was to review the scientific literature concerning the most recent epidemiological data on chronic pain in Europe as a whole using a systematic review methodology while following standardised processes and methods recommended by the Centre for Reviews and Dissemination ${ }^{11}$.
A search strategy was designed to retrieve all relevant studies regardless of publication status or language. A series of terms related to the condition of interest were defined and their corresponding keywords combined in comprehensive strategies (available from authors) to search the following databases from 1995 to August 2009: MEDLINE, EMBASE, The Cochrane Library, CRD Databases (DARE, HTA, NHS EED), and the GIN database. Additionally, reference lists of those studies deemed relevant to the review were checked. Additional data were obtained by searching national statistic and health survey websites.

Primary studies or systematic reviews of studies providing epidemiological data about non-cancer chronic pain in Europe as a whole were considered for inclusion. Chronic pain was defined as a painful condition lasting at least 3 months or those chronic conditions associated with chronic pain; including musculoskeletal pain, neuropathic pain, fibromyalgia, osteoarthritis, and rheumatoid arthritis. Studies that solely concerned children or adolescents were excluded, as well as conditions such as migraine and headache, angina pectoris, cancer pain, or pain associated with specific disease conditions (e.g., multiple sclerosis).

After defining a list of clinical questions that addressed basic issues related to chronic pain (e.g., prevalence, incidence, treatment adequacy, compliance and satisfaction with treatment, economic impact and impact on quality of life), two authors independently inspected the retrieved references for eligibility and determined their relevance. Included studies were categorised to obtain a list of relevant studies per question and then the most relevant and representative were selected. The goal was to select studies where the methodology ensured that the sample population was representative of the current pan-European population. Therefore, preference was given to large surveys of the general population where the demographic characteristics of the sample were likely to be comparable to the target population. Preference was also given to recent surveys as the demographic, socioeconomic and psychological characteristics were more likely to represent a present-day European population than studies conducted, for example, 15 years ago. In short, studies were selected according to the following criteria: sample size, representativeness of the target population, recency, and methodological quality. One author assessed the methodological quality of each included study and a second checked the assessment for accuracy. Disagreements were resolved by consensus. This assessment was used for descriptive purposes, which allowed a transparent evaluation of the overall literature quality. A basic set of criteria related to potential sources of bias in observational studies: description of study design, eligibility criteria explicitness, sample representativeness of target population, adequate description of study outcomes, adequate description of statistical analysis including adjustments for confounders, adequate description of 
Table 1. The following quality criteria were used for the assessment of the observational studies: (criteria to be answered with yes/no/unclear) ${ }^{24}$.

\begin{tabular}{|c|c|}
\hline Criteria & Explanation: criterion is adequate if: \\
\hline Adequate description of study design and setting & Authors reported study design, setting and period of study \\
\hline $\begin{array}{l}\text { Adequate description of eligibility criteria (incl. description of } \\
\text { diagnostic criteria for chronic pain condition) }\end{array}$ & $\begin{array}{l}\text { Authors reported inclusion/exclusion criteria with diagnostic criteria to } \\
\text { confirm diagnosis or confirmation that the doctors' patients had } \\
\text { chronic pain }\end{array}$ \\
\hline $\begin{array}{l}\text { Study population is representative of target population (sample size, } \\
\text { sample selection, demographics) }\end{array}$ & $\begin{array}{l}\text { Authors described how the sample size was arrived at and how the } \\
\text { patients were selected and the demographics of the sample should be } \\
\text { described as comparable to the target population. For surveys, an } \\
\text { attempt should be made to compare non-responders to responders }\end{array}$ \\
\hline $\begin{array}{l}\text { Adequate description of outcomes (and how/how often measured), } \\
\text { exposures, predictors }\end{array}$ & $\begin{array}{l}\text { Authors describe how they measure the outcome and clear definitions are } \\
\text { given for key terms }\end{array}$ \\
\hline $\begin{array}{l}\text { Adequate description of statistical methods (incl. description of } \\
\text { potential confounders and effect modifiers and how they were } \\
\text { dealt with) }\end{array}$ & $\begin{array}{l}\text { Authors describe their statistical methods and describe potential } \\
\text { confounders or effect modifiers and how they were dealt with }\end{array}$ \\
\hline Adequate description of study participants & $\begin{array}{l}\text { Authors provide more than just age and gender (pain duration, occupa- } \\
\text { tions, pain type, etc.) }\end{array}$ \\
\hline $\begin{array}{l}\text { Adequate description of losses to follow-up (for longitudinal studies), } \\
\text { loss to follow-up less than 10\% at } 12 \text { months or less than } 25 \% \text { for } \\
\text { longer follow-up }\end{array}$ & $\begin{array}{l}\text { Authors clearly describe the losses to follow-up or if the loss is }<10 \% \text { by } \\
12 \text { months and }<25 \% \text { for periods longer than } 12 \text { months. } \\
\text { NA for cross sectional studies }\end{array}$ \\
\hline $\begin{array}{l}\text { Results reported as unadjusted and confounder-adjusted including } \\
\text { precision }\end{array}$ & $\begin{array}{l}\text { Authors report their results as unadjusted or confounder adjusted } \\
\text { (or equivalent language - univariate, multivariate) and they provide } \\
\text { precision (e.g., SE or SD, Cls). Authors should also indicate what } \\
\text { confounders were adjusted for and why they were included }\end{array}$ \\
\hline
\end{tabular}

study participants, and handling of losses to follow up (Table 1). A study was assessed as high quality if the authors met all the criteria or missed only one criterion, medium quality if they missed two or three criteria and low quality if they missed four or more criteria. The aim was to give preference to medium to high quality studies that examined a large segment of the general European population although lower quality studies were included in the absence of higher quality studies.

Data were extracted to standardised forms and checked by a second author. The most relevant information was collected that contributed information to each of the defined clinical questions, and these data were registered in tables jointly with a study's quality details. The results were summarised from included studies classifying them by defined questions. Rather than a systematic exhaustive approach, this review employed a narrative method to synthesise the most relevant, reliable and recent epidemiologic studies about chronic pain in Europe.

As there was a dearth of studies that were relevant to chronic non-cancer pain, studies were included that explicitly or implicitly included those with chronic cancer-related pain. For clarity, the following terminology was employed: 'any chronic pain' included those with mild pain; 'general chronic pain' included those with cancerrelated pain.

\section{Results}

From the 16619 references retrieved from the searches, 1056 full text articles were selected that were assessed in detail. From these, 45 primary studies were identified as well as systematic reviews that provided potential relevant information about chronic pain in Europe as a whole. No studies were identified that reported chronic pain incidence or the economic impact of chronic pain from a healthcare system perspective for Europe (Table 2). There were few large studies that examined chronic pain within the general population of Europe and, as such, any identified study that reported relevant chronic pain outcomes for a pan-Europe population was included. Out of 45 identified publications, 12 primary studies were selected (Table 3). A list of the 33 excluded primary studies and systematic reviews, along with the reasons for exclusion, can be viewed in Table 4. The main reason for exclusion was that population samples included those with acute pain and chronic pain data were not reported separately.

Out of the 12 selected studies, only Alonso et al. (2004) was judged as high quality with representative results ${ }^{12}$. For the remaining, five were judged to be medium quality and six as low quality primarily because of inadequate reporting of participant eligibility, participant characteristics, and statistical methodology (Table 3). The representativeness of the results from these 11 studies was assessed as unclear because authors did not compare their samples to target populations and/or participants were not compared to those who refused to participate.

\section{Prevalence of chronic pain}

Eight selected studies reported the prevalence of chronic pain in Europe although only Alonso et al. (2004) was judged as representative ${ }^{12}$. A single study presented prevalence data on moderate-to-severe chronic non-cancer 
Table 2. Number of identified and selected studies by research question.

\begin{tabular}{lrc}
\hline Research question & $\begin{array}{c}\text { Studies } \\
\text { identified }\end{array}$ & $\begin{array}{c}\text { Studies } \\
\text { selected }\end{array}$ \\
\hline What is the prevalence of chronic pain conditions in Europe? & 10 & 8 \\
What is the incidence of chronic pain conditions in Europe? & 0 & 0 \\
How many European chronic pain patients present for treatment? & 4 & 2 \\
What percentage of European chronic pain patients are untreated or inadequately treated? & 1 & 1 \\
How many European chronic pain sufferers have inadequate pain control? & 2 & 2 \\
How many European chronic pain patients get treated broken down by treatment? & 4 & 2 \\
What are the frequencies of drug (per WHO class), non-drug, and combined treatments in Europe? & 4 & 2 \\
What is the compliance of treated chronic pain patients in Europe? & 1 & 1 \\
What is patients' satisfaction about drug treatments in Europe? & 2 & 2 \\
In Europe, what is the impact of chronic pain on: & 5 \\
Quality of life? & 3 & 2 \\
Activities of daily living? & 8 \\
Depression and other mental illness? & 2 & 3 \\
Isolation and helplessness? & 3 \\
In Europe, what is the economic impact of chronic pain: & 4 \\
On the number of days off work? & 1 \\
On incapacity benefits? & 2 \\
From a societal perspective? & 0 & 3 \\
From a healthcare system perspective? & 2 \\
From a patient perspective? & 2 \\
\hline
\end{tabular}

pain reporting a 1 -month prevalence estimate of $19 \%$ $(\text { Table } 5)^{2,3}$. For the prevalence of any general chronic pain, the most relevant estimate was a point prevalence of $17.1 \%^{7-9}$.

Other studies focused on specific pain conditions: they estimated a lifetime prevalence of $6 \%$ and $9 \%$ for upper and lower chronic back pain, respectively; a lifetime prevalence of $5 \%$ for chronic neck pain; a point prevalence of $13 \%, 6.7 \%$ and $2.9 \%$ for chronic widespread pain without fatigue, with fatigue and for fibromyalgia, respectively ${ }^{13,14}$. The remaining studies that reported a prevalence estimate for specific pain conditions listed a range by country rather than a prevalence estimate for Europe as a whole (Table 5) $)^{10,12,15}$.

The authors were unable to identify any study that reported the incidence of chronic pain conditions in Europe as a whole.

\section{Impact of chronic pain}

Seven selected studies, all with unclear representativeness, reported a considerable impact of chronic pain on aspects of quality of life. Chronic pain negatively affected overall patient perception of general health, interfered considerably with everyday activities as a function of pain severity, was associated with depressive symptoms, and dramatically and negatively affected relationships and interactions with others (Table 5). The results from five selected studies, all with unclear representativeness, also suggested that chronic pain had an economic impact on individuals, society and healthcare utilisation $(\text { Table 5) })^{2,3,10,16,17}$.

\section{Impact of chronic pain on quality of life, activities of daily living and depression}

In a majority of moderate-to-severe chronic non-cancer pain sufferers, pain severely affected daily activities including the ability to sleep, exercise, lift objects and do household chores and a substantial portion were less able or no longer able to maintain relationships with family and friends and were less able or no longer able to attend social functions $s^{2,3}$. Those with any general chronic pain may be more likely to rate their health status as fair-to-poor compared to those not experiencing persistent pain ${ }^{15}$. There was a clear association between depressive symptoms and chronic pain that increased with the number of depressive symptoms ${ }^{7,8}$. For those with pain due to knee arthrosis, a substantial proportion (22\%) felt they were a burden to others and small percentage $(5.1 \%)$ no longer wanted to see friends ${ }^{18}$.

Those with any general chronic neuropathic pain estimated that their overall health rating would improve dramatically if they were free of pain ${ }^{16}$. Similar statistically significant results were observed for subpopulations with trigeminal neuralgia, painful diabetic neuropathy and post-herpetic neuralgia ${ }^{16,19-21}$. Interference with functioning and well-being also was significantly associated with increasing pain severity $(p \leq 0.001)$.

\section{Economic impact of chronic pain on individuals, society and healthcare utilisation}

The mean number of work days lost due to moderateto-severe chronic non-cancer pain in the last 6 months was 7.8 days and $22 \%$ had lost at least 10 work days ${ }^{2,3}$. 


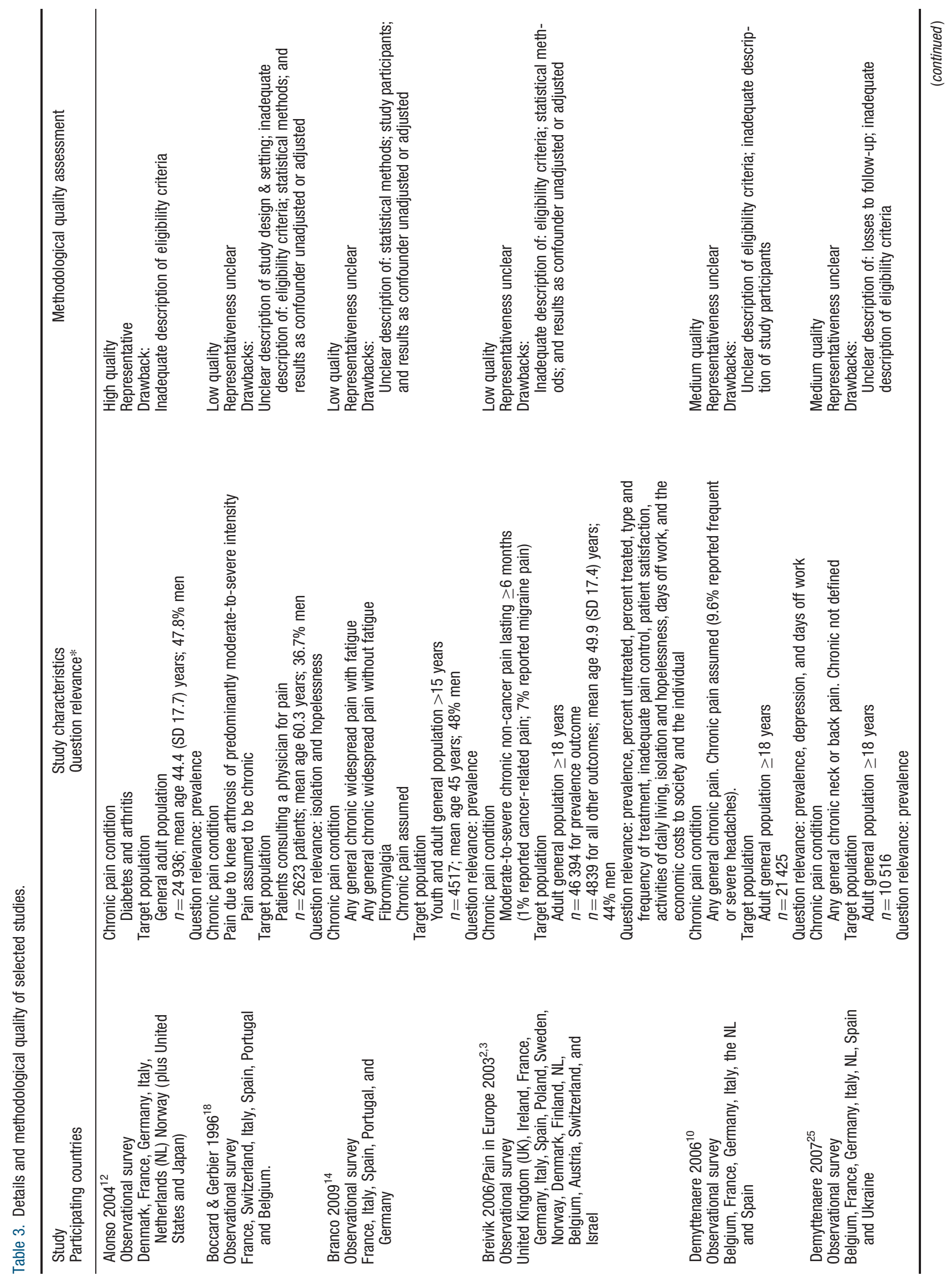




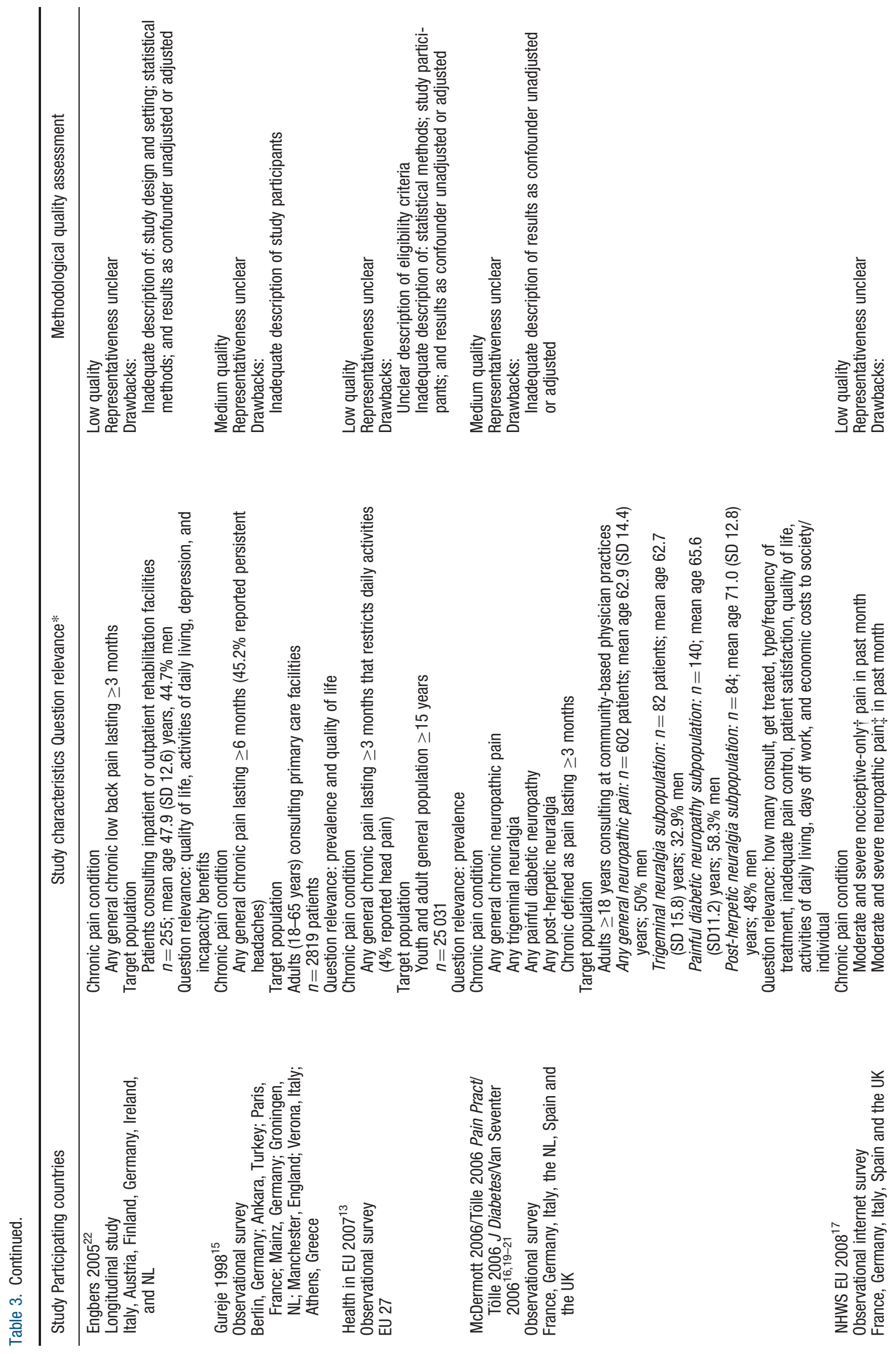




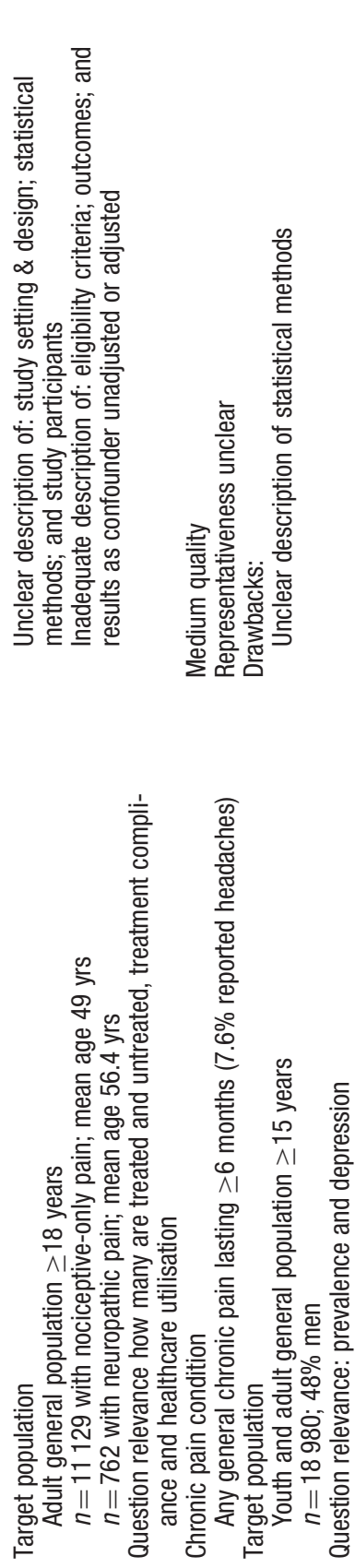

Table 4. Excluded studies with the primary reason for exclusion.

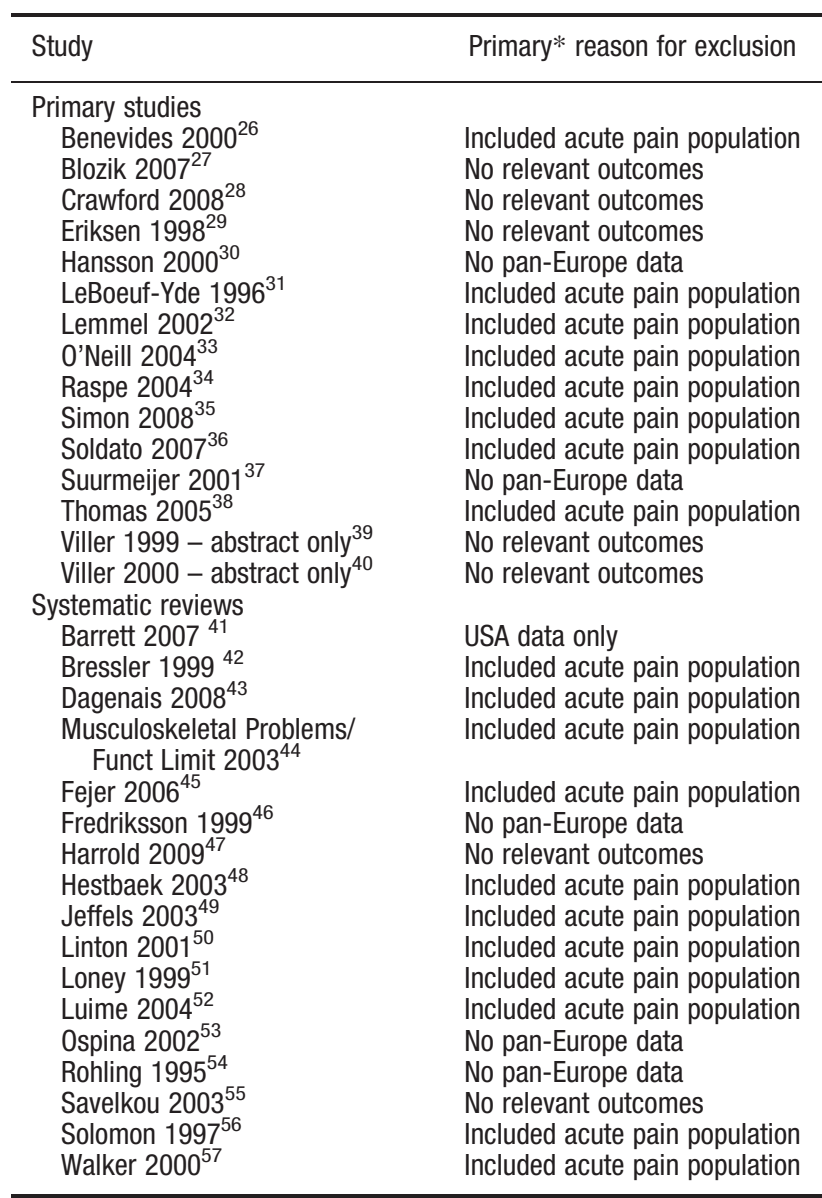

*Only the primary reason for exclusion is listed here. All the excluded studies had compound reasons for exclusion including: very small sample size; sample not representative of general population; and original studies published $<1995$.

Although $55 \%$ of this sample lost no work days at all, $26 \%$ stated that pain impacted on their employment in some way. Those with any general chronic pain lost on average 3.6 work days in the past 30 days and had lost a greater average number if they also had a major depressive disorder ${ }^{10}$. Only $52 \%$ of rehabilitation patients in Europe with any general chronic low back pain were working full or part time ${ }^{22}$. A total of $6.7 \%$ of this population sample were on sick leave although it was not apparent that chronic low back pain was the primary cause.

For those with any general chronic neuropathic pain, the mean number of work days lost in the previous four weeks was 5.5 days $^{16}$. A majority (57.1\%) stated that their pain had not impacted on their employment status.

No study was identified that reported on the economic impact of chronic pain on healthcare systems in Europe. However, data from an European study on those with pain in the previous month may give insight into the relative healthcare utilisation by those with general chronic pain: for those who experienced moderate nociceptive-only and 
Table 5. Prevalence, impact on quality of life, activities of daily living and depression, and economic impact of chronic pain in Europe.

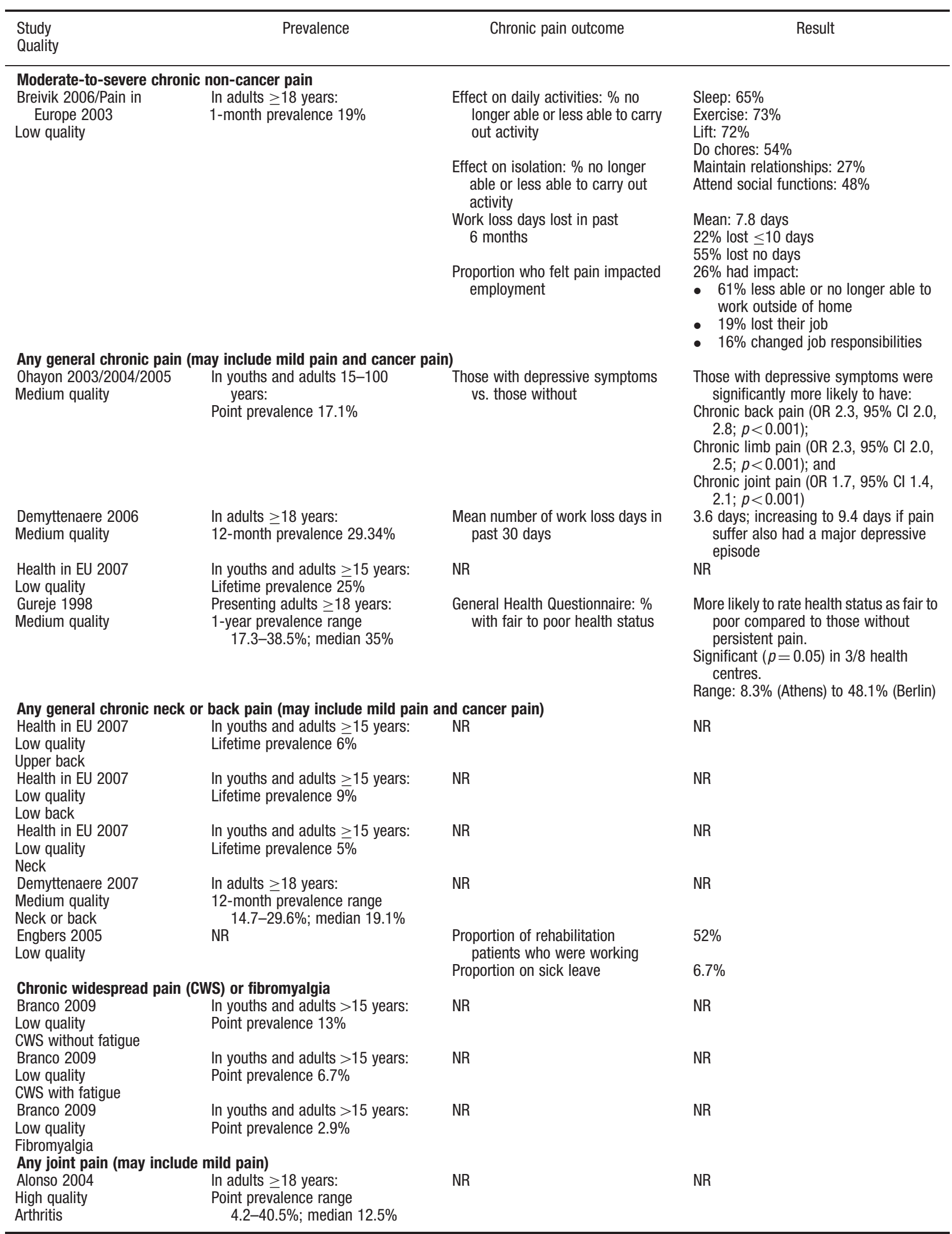


Table 5. Continued.

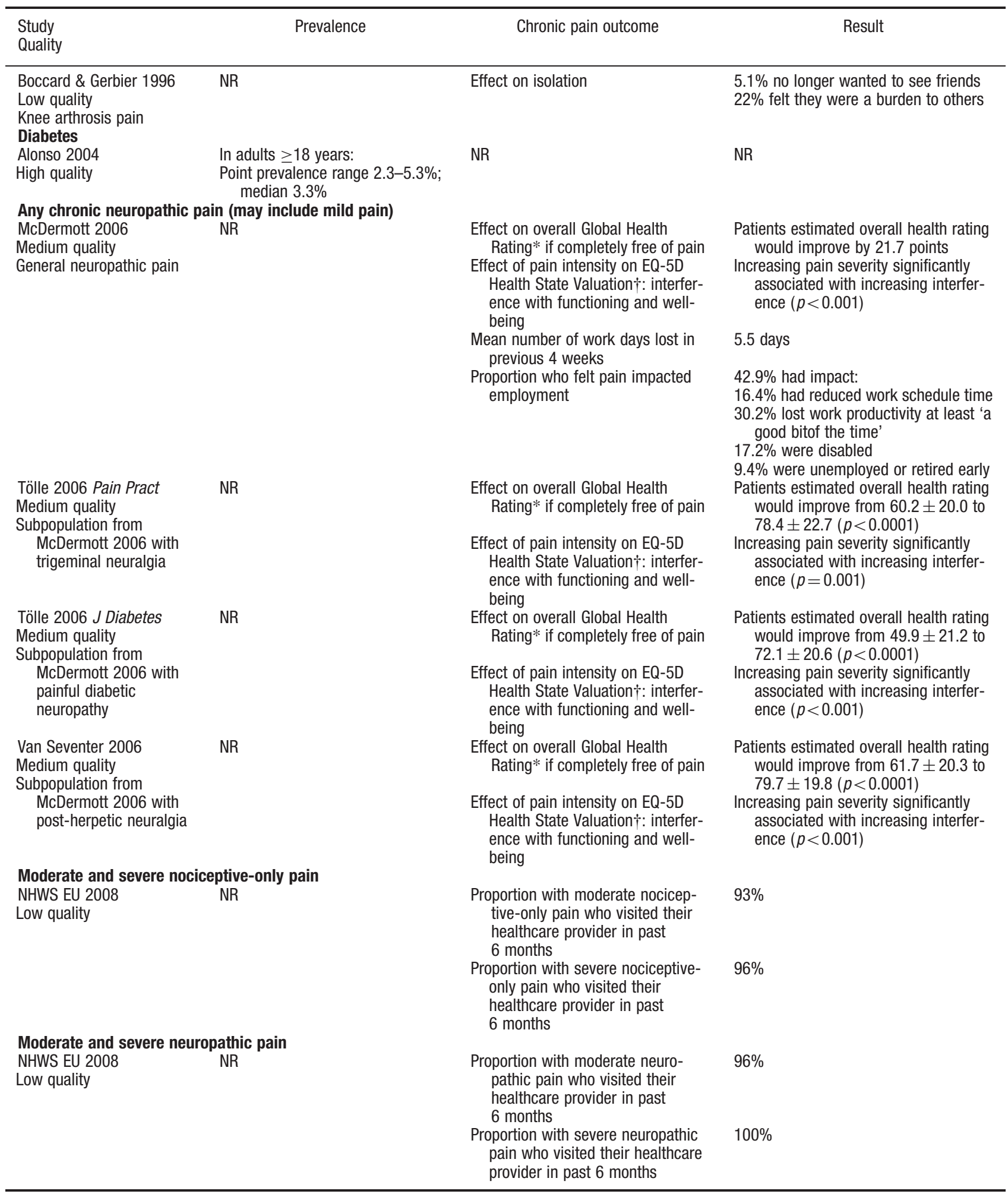

*Global Health Rating of 0 to 100 where 0 indicated worst possible health and 100 indicated perfect health.

$\dagger E Q-5 D$ Health State Valuation utility scale of -0.59 to 1.00 , with lower scores indicating a poorer quality of life.

$\mathrm{NR}$ - not reported or data not relevant to this review. 
neuropathic pain in the previous month, respectively 93\% and 96\% visited their healthcare provider in the past 6 months ${ }^{17}$. For those with severe pain, the proportion was slightly higher at $96 \%$ and 100\% respectively. In contrast, $84 \%$ of the general European adult population visited their healthcare provider in the past 6 months.

\section{Chronic pain presentation, treatment, pain control and compliance with treatment}

Three selected studies, all with unclear representativeness, reported on chronic pain presentation, treatment, pain control and treatment compliance (Table 6) 2,3,16,17,19-21.

Of those with moderate-to-severe chronic non-cancer pain, $87 \%$ had visited their doctor for their chronic pain condition at least once in the previous 6 months ${ }^{2,3}$. A total of $69 \%$ said they currently were being treated for their pain whereas $31 \%$ stated they were not being treated in any way. Approximately $78 \%$ had taken prescription pain medication at some point and $52 \%$ were currently taking prescription pain medication at the time of interview. Of those taking prescription pain medication, $40 \%$ felt their pain was controlled inadequately, $41 \%$ felt their medication was somewhat effective and $15 \%$ felt their medication was not very or not at all effective. Patient satisfaction with treatment included factors such as treatment effectiveness, tolerance and side-effects. For those with moderate-to-severe chronic non-cancer pain, $60 \%$ were satisfied with their pain treatment whereas $40 \%$ were not.

For those with any general chronic neuropathic pain, $76 \%$ had seen a physician and $28 \%$ had telephone consultations at least once in the past month for their pain ${ }^{16}$. In all, $49 \%$ had visited a pain specialist at some point and 93\% had received at least one prescription pain medication. Patient perceived effectiveness of prescription pain medication (either extremely or very effective) ranged from 27 to $42 \%{ }^{19-21}$. For those with chronic painful diabetic neuropathy, $47 \%$ were somewhat satisfied with their prescription medication ${ }^{20}$. Compliance with prescription pain medication (i.e., took medication all or most of the time) ranged from $85 \%$ in those with post-herpetic neuralgia to $94 \%$ in those with trigeminal neuralgia ${ }^{19-21}$.

For those who experienced moderate pain in the past month (nociceptive-only or neuropathic pain), the proportions that were taking prescription pain medication, were untreated for their pain and were satisfied with their prescription pain medication appeared to be similar to that reported for moderate-to-severe chronic noncancer pain (Table 6) $)^{2,3,17}$. Good or complete treatment compliance (i.e., answered 'no' to at least 3 out of 4 questions concerning compliance) ranged from $59 \%$ to $77 \%$.
No study was identified that examined the levels of inadequate chronic pain treatment in Europe (i.e., the proportion whose treatment did not meet the accepted standard for their chronic pain condition).

The most frequent WHO class drug treatments prescribed to patients with chronic pain in Europe were NSAIDs (43-44\%) and opioids (22.4-23\%) (Table 6) $)^{2,3}$. Those with any general chronic neuropathic pain also were frequently prescribed anti-epileptics $(50.7 \%)$ and anti-depressants (28.7\%) among other non-standard pain medication ${ }^{16,19-21}$. The most frequent non-drug pain treatment tried by those with moderate-to-severe general chronic pain was massage (30\%) followed by physical therapy $(21 \%)$ and acupuncture $(13 \%)^{2,3}$.

\section{Discussion}

To the authors' knowledge, this is the most comprehensive epidemiological literature review in this field for Europe as a whole. The most representative, recent and valid studies published about chronic non-cancer pain were identified and appraised, including data from the main collaborative research projects within Europe $e^{7-9,13,16,19-21}$. It was found that, despite considerable chronic pain data for individual European countries, there were few pan-European sources. Only one source reported broadly on chronic non-cancer pain, in that less than $1 \%$ of the study population reported their pain as cancer-related ${ }^{2,3}$.

The 1-month prevalence of moderate-to-severe non-cancer pain in adults was estimated at $19 \%^{2,3}$. Given that the European Union population reached 501064212 individuals in January 2010, this projects to 80 million Europeans who suffer from moderate-to-severe chronic non-cancer pain ${ }^{23}$.

Pain clearly impacted on the daily activities, employment and number of work days lost for chronic non-cancer pain sufferers in Europe ${ }^{2,3,10,16}$. For those with any general chronic pain, pain affected quality of life and was significantly associated with anxiety and depression ${ }^{7-9,15,16,19-21}$. Sufferers regularly used healthcare resources although a high portion appeared to be not be treated in any way $2,3,16,19-21$. Inadequate pain control was commonly reported along with dissatisfaction with pain treatments, which predominantly included NSAIDs. For chronic neuropathic pain, treatment compliance was reportedly high despite patient-perceived ineffectiveness.

\section{Limitations of this review}

The data used in this review came from large population surveys of multiple European countries and were adjusted for the age and sex of the respondents. Despite these strengths, only one study explicitly compared their population sample with the general adult population ${ }^{12}$. 


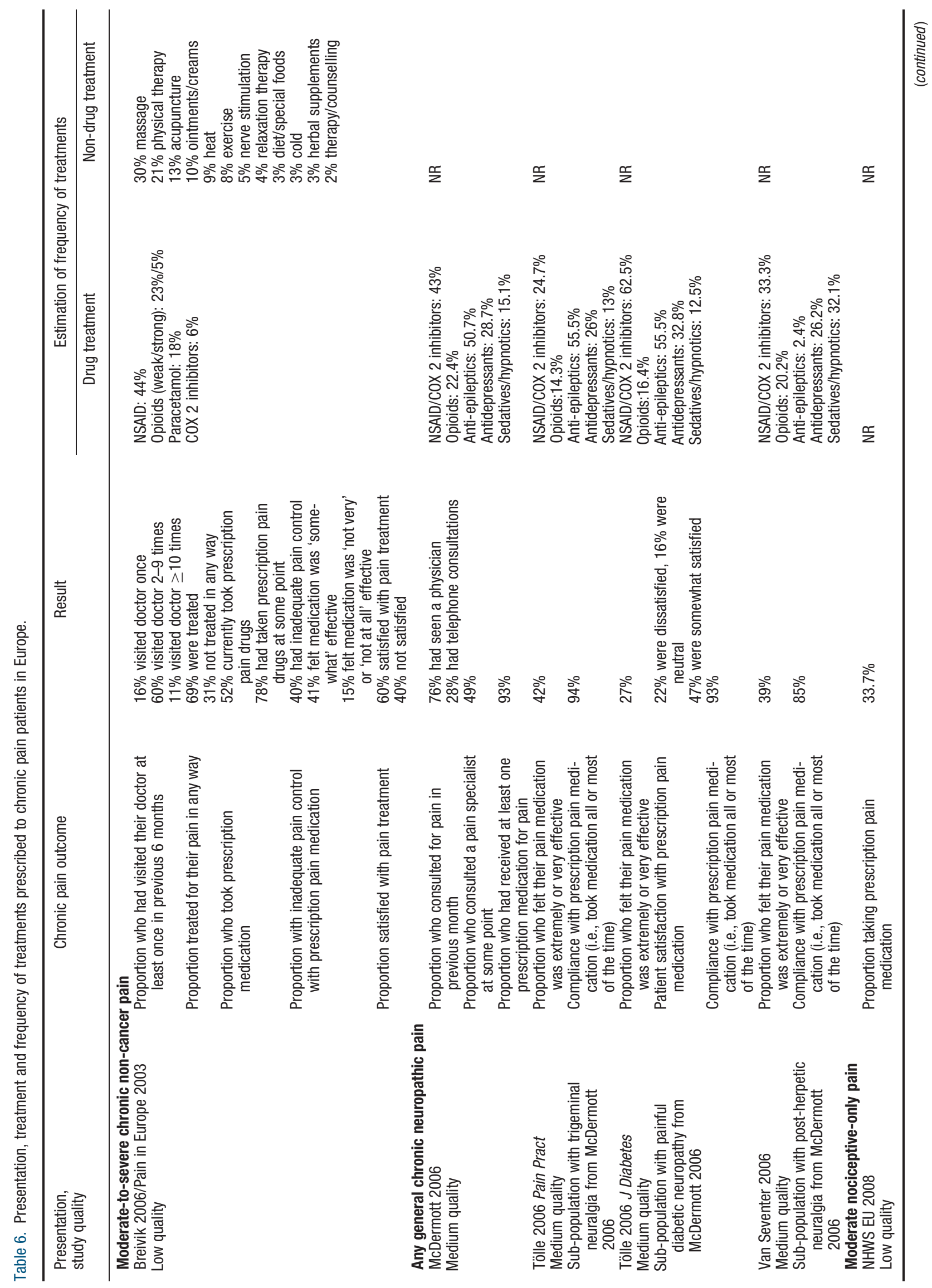




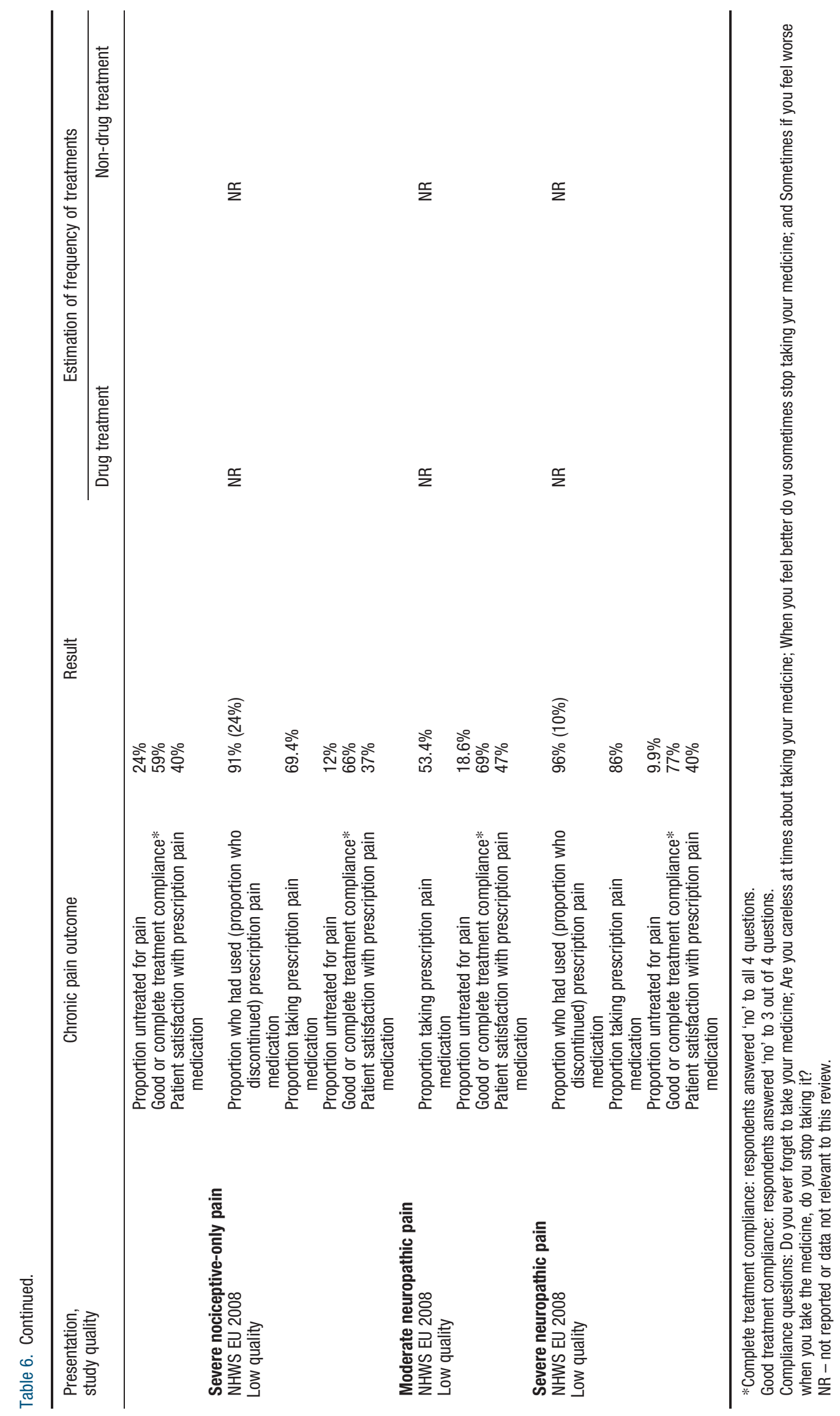


As such, the representativeness of the above results cannot be assured. Another major shortcoming for the majority of included studies was a lack of statistical comparison with any other population sample: it was not clear whether the impact of chronic pain was any different than acute/ sub-acute pain or the absence of pain.

Studies were excluded that solely concerned migraines or headaches because, while they can persist over long time periods and some could be considered chronic pain, a large proportion would be highly intermittent and probably should be considered acute. Studies concerning specific disease conditions that have associated pain (e.g., multiple sclerosis) were also excluded. With these exclusions in mind, the authors acknowledge that the true prevalence of chronic non-cancer pain may be underestimated in this review. However, studies that examined chronic pain as a broad category did not exclude those with migraines or headache, so these data should be considered inclusive $^{2,3,8-10,13,15}$.

\section{Conclusion}

Despite the lack of high quality studies, the above data clearly underlines the need for healthcare decision makers in Europe to gather further epidemiological data related to chronic non-cancer pain and chronic pain in general. The present review has identified some gaps in the literature: reliable estimates for the prevalence and incidence of chronic pain in Europe are lacking and no identified study reported the cost of chronic noncancer pain in accepted economic terms (e.g., QALYs) or the cost from the healthcare perspective for Europe as a whole.

The variability in the collected data, most notably for prevalence, shows an inconsistency in defining chronic pain and measuring its impact. As well, cancer-related and non-cancer chronic pain typically require different treatment approaches and, as such, these populations should be studied separately. Finally, the measurements of impact, both on quality of life and economic outcomes, should be placed in context such that chronic pain populations are compared to either the general population or other pain sufferers.

The outcome of these efforts should be a reliable source of epidemiological data to define the burden of the disease within Europe. To achieve this objective, the roles of European healthcare research agencies, governments and public funders are of paramount importance. New research on this field could focus on the clinical questions that remain to be answered, including prioritising research with a higher impact on public health, and funding research projects with high scientific quality.

\section{Transparency}

\section{Declaration of funding}

This study was funded by Grünenthal, Aachen. This funding source did not have any influence on the conduct and reporting of this study.

\section{Declaration of financial/other relationships}

The authors declare that there are no conflicts of interest.

Some peer reviewers receive honoraria from CMRO for their review work. The peer reviewers of this paper have disclosed that they have no relevant financial relationships.

\section{Acknowledgement}

The authors have disclosed that they had no outside editorial assistance in preparing this manuscript.

\section{References}

1. International Association for the Study of Pain. 2010 [cited 2010 September] Available at: http://www.iasp-pain org//AM/Template.cfm?Section=Home

2. Breivik H, Collett B, Ventafridda V, et al. Survey of chronic pain in Europe: prevalence, impact on daily life, and treatment. Eur J Pain 2006;10:287-333

3. NFO Worldgroup. Pain in Europe Report. 2003 [cited 2010 September] Available at: http://www.paineurope.com/

4. Nicholson B. Responsible prescribing of opioids for the management of chronic pain. Drugs 2003;63:17-32

5. Collett BJ. Chronic opioid therapy for non-cancer pain. Br J Anaesth 2001; 87:133-43

6. Furlan AD, Sandoval JA, Mailis-Gagnon A, et al. Opioids for chronic noncancer pain: a meta-analysis of effectiveness and side effects. CMAJ 2006; 174:1589-94

7. Ohayon MM, Schatzberg AF. Using chronic pain to predict depressive morbidity in the general population. Arch Gen Psychiatry 2003;60:39-47

8. Ohayon MM. Specific characteristics of the pain/depression association in the general population. J Clin Psychiatry 2004;65(Suppl 12):5-9

9. Ohayon MM. Relationship between chronic painful physical condition and insomnia. J Psychiatr Res 2005;39:151-9

10. Demyttenaere K, Bonnewyn A, Bruffaerts R, et al. Comorbid painful physical symptoms and depression: prevalence, work loss, and help seeking. J Affect Disord 2006;92:185-93

11. University of York Centre for Reviews and Dissemination. Systematic Reviews: CRD's guidance for undertaking reviews in health care. 2009 [cited 2010 September] Available at: http://www. york.ac.uk/inst/crd/ guidance.htm

12. Alonso J, Ferrer M, Gandek B, et al. Health-related quality of life associated with chronic conditions in eight countries: results from the International Quality of Life Assessment (IQOLA) Project. Quality of Life Research 2004; 13:283-98

13. European Commission. Health in the European Union. Special Eurobarometer 272e/Wave 66.2 - TNS Opinion \& Social, 2007

14. Branco JC, Bannwarth B, Failde I, et al. Prevalence of fibromyalgia: a survey in five european countries. Semin Arthritis Rheum 2009:39:448-53

15. Gureje 0, Von K, Simon GE, et al. Persistent pain and well-being: a World Health Organization Study in Primary Care. [erratum appears in JAMA 1998 Oct 7:280:1142]. JAMA 1998:280:147-51

16. McDermott AM, Tölle TR, Rowbotham DJ, et al. The burden of neuropathic pain: results from a cross-sectional survey. Eur J Pain 2006;10:127-35

17. Consumer Health Sciences. National Health and Wellness Survey [EU]. 2008. Available at: http://www.chsinternational.com/[Last accessed 21 December 2010] 
18. Boccard E, Gerbier JL. Pain and its expression in six European countries: a survey. Pain Clinic 1996;9:77-88

19. Tölle T, Dukes E, Sadosky A. Patient burden of trigeminal neuralgia: results from a cross-sectional survey of health state impairment and treatment patterns in six European countries. Pain Pract 2006:6:153-60

20. Tölle $T, X u X$, Sadosky AB. Painful diabetic neuropathy: a cross-sectional survey of health state impairment and treatment patterns. J Diabetes Complicat 2006;20:26-33

21. van Seventer R., Sadosky A, Lucero M, et al. A cross-sectional survey of health state impairment and treatment patterns in patients with postherpetic neuralgia. Age Ageing 2006;35:132-7

22. Engbers LH, Vollenbroek-Hutten MM, van Harten WH. A comparison of patient characteristics and rehabilitation treatment content of chronic low back pain (CLBP) and stroke patients across six European countries. Health Policy 2005;71:359-73

23. European Commission. Eurostat: your key to European Statistics. [2010] [cited 2010 Sept. 15] Available at: http://epp. eurostat.ec.europa.eu

24. Strengthening the reporting of observational studies in epidemiology (STROBE) checklist. 2007 [cited 2010 Sept.] Available at: http://www. strobe-statement.org Excluded studies

25. Demyttenaere K, Bruffaerts R, Lee S, et al. Mental disorders among persons with chronic back or neck pain: Results from the world mental health surveys. Pain 2007:129:332-42

26. Benavides FG, Benach J, ez-Roux AV, et al. How do types of employment relate to health indicators? Findings from the second European survey on working conditions. J Epidemiol Community Health 2000;54:494-501

27. Blozik E, Stuck AE, Niemann S, et al. Geriatric Pain Measure short form: development and initial evaluation. J Am Geriatr Soc 2007;55:2045-50

28. Crawford B, Bouhassira D, Wong A, et al. Conceptual adequacy of the neuropathic pain symptom inventory in six countries. Health Qual Life Outcomes 2008:6:62

29. Eriksen HR, Svendsrod R, Ursin G, et al. Prevalence of subjective health complaints in the Nordic European countries in 1993. Eur J Public Health 1998;8:294-8

30. Hansson TH, Hansson EK. The effects of common medical interventions on pain, back function, and work resumption in patients with chronic low back pain: A prospective 2-year cohort study in six countries. Spine 2000; 25:3055-64

31. Leboeuf-Yde C, Klougart N, Lauritzen T. How common is low back pain in the Nordic population? Data from a recent study on a middle-aged general Danish population and four surveys previously conducted in the Nordic countries. Spine 1996;21:1518-25

32. Lemmel EM, Leeb B, De B, et al. Patient and physician satisfaction with aceclofenac: results of the European Observational Cohort Study (experience with aceclofenac for inflammatory pain in daily practice). Aceclofenac is the treatment of choice for patients and physicians in the management of inflammatory pain. Curr Med Res Opin 2002;18:146-53

33. O'Neill TW, Cockerill W, Matthis C, et al. Back pain, disability, and radiographic vertebral fracture in European women: a prospective study. Osteoporos Int 2004;15:760-5

34. Raspe $\mathrm{H}$, Matthis $\mathrm{C}$, Croft $\mathrm{P}$, et al. Variation in back pain between countries: the example of Britain and Germany. Spine (Phila Pa 1976) 2004;29:1017-21

35. Simon M, Tackenberg $P$, Nienhaus $A$, et al. Back or neck-pain-related disability of nursing staff in hospitals, nursing homes and home care in seven countries-results from the European NEXT-Study. Int J Nurs Stud 2008; 45:24-34

36. Soldato $\mathrm{M}$, Liperoti $\mathrm{R}$, Landi $\mathrm{F}$, et al. Non malignant daily pain and risk of disability among older adults in home care in Europe. Pain 2007;129:304-10
37. Suurmeijer TP, Waltz M, Moum T, et al. Quality of life profiles in the first years of rheumatoid arthritis: results from the EURIDISS Iongitudinal study. Arthritis Rheum 2001;45:111-21

38. Thomas E, van der Windt DAWM, Hay EM, et al. Two pragmatic trials of treatment for shoulder disorders in primary care: generalisability, course, and prognostic indicators. Ann Rheum Dis 2005;64:1056-61

39. Viller F, Guillemin F, Briancon S, et al. Compliance to drug treatment of patients with rheumatoid arthritis: a 3 year longitudinal study. J Rheumatol 1999;26:2114-22

40. Viller F, Guillemin F, Briancon $\mathrm{S}$, et al. Compliance with drug therapy in rheumatoid arthritis. A longitudinal European study. Joint Bone Spine 2000;67:178-82

41. Barrett AM, Lucero MA, Trong Le MPH, et al. Epidemiology, public health burden, and treatment of diabetic peripheral neuropathic pain: a review. Pain medicine 2007;8(Suppl 2):S50-62

42. Bressler HB, Keyes WJ, Rochon PA, et al. The prevalence of low back pain in the elderly. A systematic review of the literature. Spine 1999:24:1813-19

43. Dagenais S, Caro J, Haldeman S. A systematic review of low back pain cost of illness studies in the United States and internationally. Spine J 2008:8:8-20

44. European Commission. Musculoskeletal problems and functional limitations: the great public health challenge for the 21st century. S12.297217. 2003. Oslo, Norway

45. Fejer R, Kyvik KO, Hartvigsen J. The prevalence of neck pain in the world population: A systematic critical review of the literature. Eur Spine J 2006; 15:834-48

46. Fredriksson $\mathrm{K}$, Alfredsson L, Koster M, et al. Risk factors for neck and upper limb disorders: results from 24 years of follow up. Occup Environ Med 1999; 56:59-66

47. Harrold LR, Andrade SE. Medication adherence of patients with selected rheumatic conditions: a systematic review of the literature. Semin Arthritis Rheum 2009;38:396-402

48. Hestbaek L, Leboeuf-Yde C, Manniche C. Low back pain: what is the longterm course? A review of studies of general patient populations. Eur Spine $J$ 2003;12:149-65

49. Jeffels K, Foster N. Can aspects of physiotherapist communication influence patients' pain experiences: a systematic review. Phys Ther Rev 2003;8: $197-210$

50. Linton SJ. Occupational psychological factors increase the risk for back pain: a systematic review. J Occup Rehabil 2001;11:53-66

51. Loney PL, Stratford PW. The prevalence of low back pain in adults: a methodological review of the literature. Phys Ther 1999;79:384-96

52. Luime JJ, Koes BW, Hendriksen IJ, et al. Prevalence and incidence of shoulder pain in the general population; a systematic review. Scand J Rheumatol 2004:33:73-81

53. Ospina M, Harstall C. Prevalence of chronic pain: an overview. Alberta Heritage Foundation for Medical Research. HTA 29. December 2002. ISBN 1-896956-62-9

54. Rohling ML, Binder LM, Langhinrichsen-Rohling J. Money matters: a metaanalytic review of the association between financial compensation and the experience and treatment of chronic pain. Health Psychol 1995;14:537-47

55. Savelkoul M, de Witte L, Post M. Stimulating active coping in patients with rheumatic diseases: a systematic review of controlled group intervention studies. Patient Educ Couns 2003;50:133-43

56. Solomon DH, Bates DW. Panush RS, et al. Costs, outcomes, and patient satisfaction by provider type for patients with rheumatic and musculoskeletal conditions: a critical review of the literature and proposed methodologic standards. Ann Intern Med 1997;127:52-60

57. Walker BF. The prevalence of low back pain: a systematic review of the literature from 1966 to 1998. J Spinal Disord 2000:13:205-17 